Proceedings of the 11th Polish-Japanese Joint Seminar on Micro and Nano Analysis, Gniew, September 11-14, 2016

\title{
Microdeformation Processes in Soft Magnetic Compounds
}

\author{
R. Bidulský $\bar{a}^{a *}$, J. Bidulskáa ${ }^{a}$, P. Petroušek ${ }^{a}$, A. Fedorikováa ${ }^{a}$, E. Dudrová $^{b}$ \\ AND M. ACTIS GRANDE ${ }^{c}$ \\ ${ }^{a}$ Technical University of Košice, Faculty of Metallurgy, Institute of Materials, Letná 9, 04200 Košice, Slovakia \\ ${ }^{b}$ Institute of Materials Research, Slovak Academy of Sciences, Watsonova 45, 04001 Košice, Slovakia \\ ${ }^{c}$ Department of Applied Science and Technology, Politecnico di Torino, \\ Viale Teresa Michel, 5, 15121, Alessandria, Italy
}

\begin{abstract}
Porosity can be defined in different ways. The most frequently used definition is the total porosity, which is the total volume fraction of empty space in the specimen. The presence of pores strongly affects the fracture mode. Besides the evaluation of geometry and quality of connections, fractographic analysis enables a quantification of the important microstructural characteristics of the plane porosity. This quantity allows to quantify the existing relations between microstructure and properties. The fractographic evaluation of the distribution of microdeformation processes in the volume of experimental material demonstrates the influence of porosity on the concentration of deformation flows into the microvolume of connections. Plain porosity contributes to the recognition of critical microstructural defects and therefore, to enable evaluating the relationship between the processing parameters, microstructural constituents, and pores. In the fractography evaluation, the analysis of the quality of interparticle bonding using determination of elementary types of fracture facets allows to interpret the mechanical and plastic properties of investigated materials.
\end{abstract}

DOI: $10.12693 /$ APhysPolA.131.1367

PACS/topics: $75.50 .-\mathrm{y}, 81.20 . \mathrm{Ev}, 81.40 . \mathrm{Np}$

\section{Introduction}

Powder metallurgy (PM) future vision lies in the production of high-performance precision parts allowing to compete with other technologies such as the production of bulk materials. The presence of porosity, playing a very important role with great influence on properties [15], represents a real issue in PM parts.

Porosity can be defined in different ways. The most frequently used definition is the total porosity, which is the total volume fraction of empty space in the specimen [2]. This parameter is usually measured using water displacement methods. Of equal importance is the pore connectivity. The pores may be interconnected or isolated. In the case of fully interconnected porosity, only one big, very complex-shaped and branched pore is existing whereas isolated pores are distributed in the matrix [2].

The presence of pores may strongly affect the fracture mode. It has been shown early by works done by Slesar and Dudrova [3-5] that such isolated necks exhibit a different behaviour compared to the bulk material. Besides the evaluation of geometry and quality of connections, fractographic analysis enables a quantification of the important microstructural characteristics of porous material - the plane porosity $P_{X}$, defined as the percentual portion of free particle surfaces in the plane projection of the fracture surface. This quantity allows to quantify the relations between the microstructure and properties.

*corresponding author; e-mail: robert.bidulsky@tuke.sk
Microdeformation processes were evaluated according to four types, as follows:

Type 1: microlocations with zero or minimal permanent dimensional change, without a change in pore shape.

Type 2: elongation resulting from non-deformational interparticle de-bonding, developed in locations without metallic connections between particles, its formation is often accompanied by the development of deformation processes in immediate surroundings.

Type 3: elongation resulting from de-bonding of particles accompanied by plastic deformation of the matrix, correspond to locations with developed metallic connections, slip bands in the vicinity of pores are very common here.

Type 4: location with pronounced plastic deformation, corresponds to microvolumes with well-developed connections, the particle volume is also included in the deformation process.

Fractographic evaluation of the distribution of microdeformation processes in the volume of experimental material demonstrates the influence of porosity on the concentration of deformation flows into the microvolume of connections. The comparison of the plane porosity measured with image analyzing software packages and the total porosity measured through Archimedes shows that the values for the porosity are much higher for the image analyzing.

Currently, the main goal of research in PM is represented by the increase of mechanical properties, mainly in terms of bonding evolution between adjacent powder particles. The present paper is focused on the analyses of the microvolumes neck processes of different soft magnetic materials (SMM). Microdeformation processes are 
rarely taken into account in literature, particularly in the topic of SMM, leading to a substantial lack of papers in the matter.

\section{Experimental conditions}

Five different soft magnetic materials were considered in the frame of the research. Powder mixtures were homogenized using a laboratory Turbula mixer for $20 \mathrm{~min}$. Specimens with a different green density obtained using a $2000 \mathrm{kN}$ hydraulic press. Sintering and heat treatments were performed in vacuum sintering furnaces. Experimental conditions are mentioned in Table I. In this paper, the attention is focused on systems showing the highest soft magnetic materials potentiality. Fe-Ni $(\mathrm{FN}), \mathrm{Fe}-\mathrm{P}$ (P) and Fe (I) alloys are more sensitive to machining, and they have to be heat treated in order to reorganize the crystalline structure and restore the initial magnetic properties [6]. On the other hand, the insulated iron powder compounds (IIPC) represent commercially available powders $(\mathrm{S}, \mathrm{N})$ with several advantages over laminated steels [7]. The investigation of the effect of different treatment atmospheres (air, nitrogen, and vacuum), both for sintering and for the heat treatment of the sample fulfill today task of interest [8].

TABLE I

The investigated systems and processing conditions

\begin{tabular}{|c|c|c|c|c|}
\hline Mark & Composition & Mixing & Pressing & $\begin{array}{c}\text { HT or } \\
\text { sintering }\end{array}$ \\
\hline $\mathrm{P}$ & $\begin{array}{c}99.35 \% \text { PASC } 60 \\
+0.65 \% \text { AW }\end{array}$ & $\begin{array}{l}\text { Turbula, } \\
20 \mathrm{~min}\end{array}$ & $700 \mathrm{MPa}$ & $\begin{array}{l}1120^{\circ} \mathrm{C}, \\
60 \mathrm{~min}, \\
\text { vacuum }\end{array}$ \\
\hline I & $\begin{array}{c}99.35 \% \text { ABC } 100.30 \\
+0.65 \% \text { AW }\end{array}$ & $\begin{array}{l}\text { Turbula, } \\
20 \min \end{array}$ & $700 \mathrm{MPa}$ & $\begin{array}{l}1120^{\circ} \mathrm{C}, \\
60 \mathrm{~min}, \\
\text { vacuum }\end{array}$ \\
\hline FN & $\begin{array}{c}49.175 \% \mathrm{ABC} 100.30 \\
+49.175 \% \mathrm{Ni} \\
+0.65 \% \mathrm{AW}\end{array}$ & $\begin{array}{l}\text { Turbula, } \\
20 \text { min }\end{array}$ & $700 \mathrm{MPa}$ & $\begin{array}{l}1120{ }^{\circ} \mathrm{C}, \\
60 \mathrm{~min}, \\
\text { vacuum }\end{array}$ \\
\hline $\mathrm{S}$ & Somaloy $700 \mathrm{P}$ & - & $1 \mathrm{GPa}$ & $500^{\circ} \mathrm{C}$, air \\
\hline $\mathbf{N}$ & Somaloy $700 \mathrm{P}$ & - & $1 \mathrm{GPa}$ & $500{ }^{\circ} \mathrm{C}, \mathrm{N}_{2}$ \\
\hline
\end{tabular}

Densities were evaluated using the water displacement method, according to the ASTM B962-08 standard.

Different types of tests can be adopted for the characterization of the mechanical properties such as tensile, and three-point bending (TRS) tests according to the standard MPIF 41. In particular, bending tests are preferred to evaluate the strength of low ductility materials.

The microstructural characterization and porosity behavior (also fractography evaluation) were carried out on unetched specimens using an optical microscope LEICA MPEF4 equipped with an image analyzer and SEM JEOL $7000 \mathrm{~F}$ by point counting analysis (ASTM E 562). Both microstructure and porosity were investigated. An optical microscope was used for understanding the proper preparation of the specimen for later identification of microdeformation processes. It has, however, to be mentioned that the measurement of properties of components manufactured from IIPC powders may result to be quite difficult [9].
The quantitative evaluation of the fractured surfaces enabled the determination of the measure of the interparticle connections of free surfaces of particles (pore surfaces). The areas of contacts and of the free particle surfaces are evaluated as they are projected into the screen plane of the SEM. Plain porosity $P_{X}$, represent a plane projection of the free particle surfaces between which no contacts formed during the sintering process. Load bearing cross-section $P_{C S}$ represent an area of particle bonds, and their value is calculated according to the [5]:

$$
P_{C S}=100-P_{X}[\%] \text {. }
$$

Setup for SEM was: magnification $500 \times$, Fil $I=2.821$ A, $E H T=20 \mathrm{kV}, W D=15 \mathrm{~mm}$, signal $A=S E 1$. The point-counting method was carried out on the base of minimum conditions [10]: test grid for eyepiece usually employ 25 points grid, and 800 points were counted for evaluation.

\section{Results and discussion}

The evaluation of porosity by metallographic methods enables to estimate the porosity mainly in the size, shape, and distribution in a random plane [3]. Slesar et al. [5] underline that the porosity can also be estimated as a real microstructural component with specific influences on the material properties. As reported in Table II, the plasticity of investigated soft magnetic systems depends on the ability of pores to develop the macroscopic deformation in the microvolumes of the interparticle bonding.

The experimentally determined properties

TABLE II

\begin{tabular}{c|c|c|c|c|c|c}
\hline \hline & $\begin{array}{c}P_{C S} \\
{[\%]}\end{array}$ & $\begin{array}{c}P_{X} \\
{[\%]}\end{array}$ & $\begin{array}{c}\text { TRS } \\
{[\mathrm{MPa}]}\end{array}$ & $\begin{array}{c}\text { IE } \\
{[\mathrm{J}]}\end{array}$ & $\begin{array}{c}\text { Rm } \\
{[\mathrm{MPa}]}\end{array}$ & $\begin{array}{c}\text { Elongation } \\
{[\%]}\end{array}$ \\
\hline $\mathrm{P}$ & 9.07 & 90.93 & 856 & 3.4 & 428 & 5.4 \\
$\mathrm{~N}$ & 0.25 & 99.75 & 53 & 0.6 & nd & nd \\
$\mathrm{S}$ & 0.19 & 99.81 & 45 & 0.5 & nd & nd \\
$\mathrm{I}$ & 22.55 & 77.45 & 482 & 2.5 & 205 & 11.5 \\
$\mathrm{FN}$ & 21.57 & 78.43 & 444 & 10.5 & 217 & 2.7
\end{tabular}

The interparticle cold bonding in IIPC materials ( $\mathrm{S}$ and $\mathrm{N}$ ) is created only in the consolidation and provides the green strength. The following heat treatment carried out on such systems cannot be sufficient to achieve a high strength (TRS values $53 \mathrm{MPa}$ for $\mathrm{N}$, and $45 \mathrm{MPa}$ for $\mathrm{S}$, respectively). The evaluation of microdeformation processes on IIPC materials pointed out that only Type 1 exists. Fractography analysis reveals microlocations with zero or minimal permanent dimensional change, without a change in pore shape, Figs. 1 and 2.At a high value of plain porosity, the interparticle bonding is only in a few places, and load bearing cross-section is so weak. Local stress concentrations occur around pores and impurities may cause microscopic yielding. As a result, the loss of their plastic stability starts sooner than 


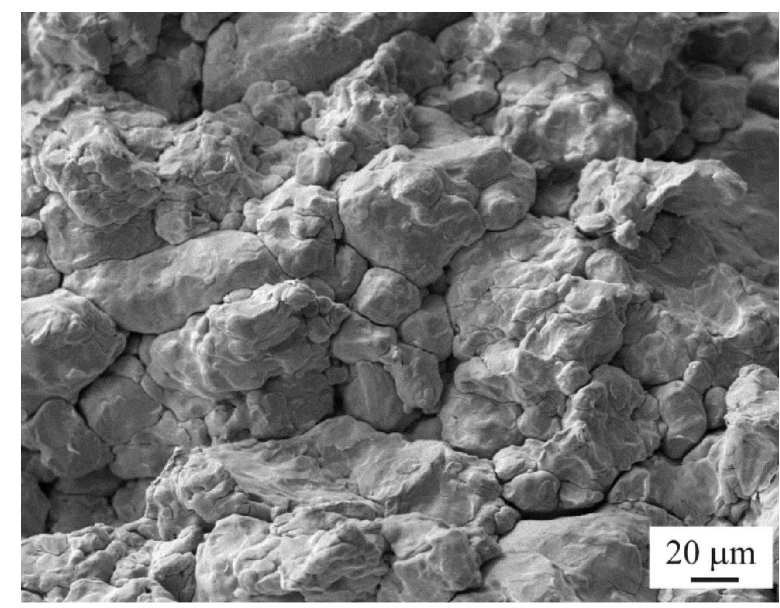

Fig. 1. Microdeformation processes of system S.

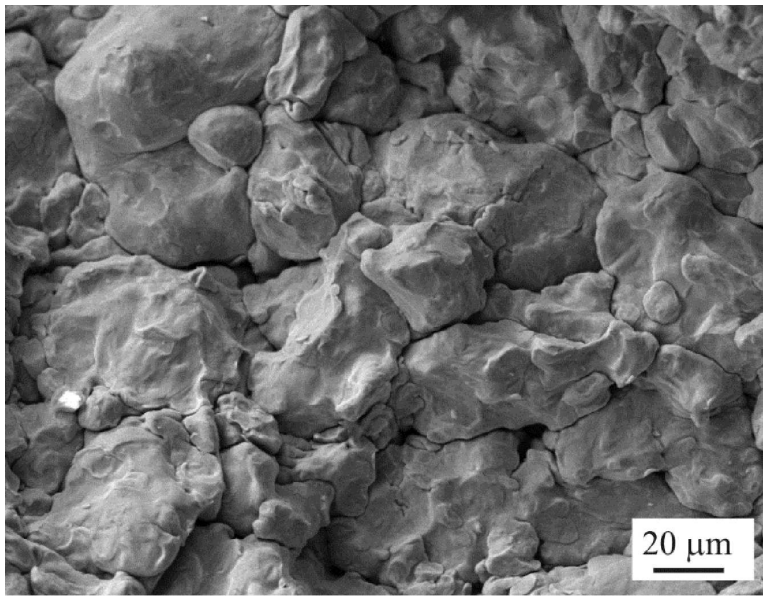

Fig. 2. Microdeformation processes of system N.

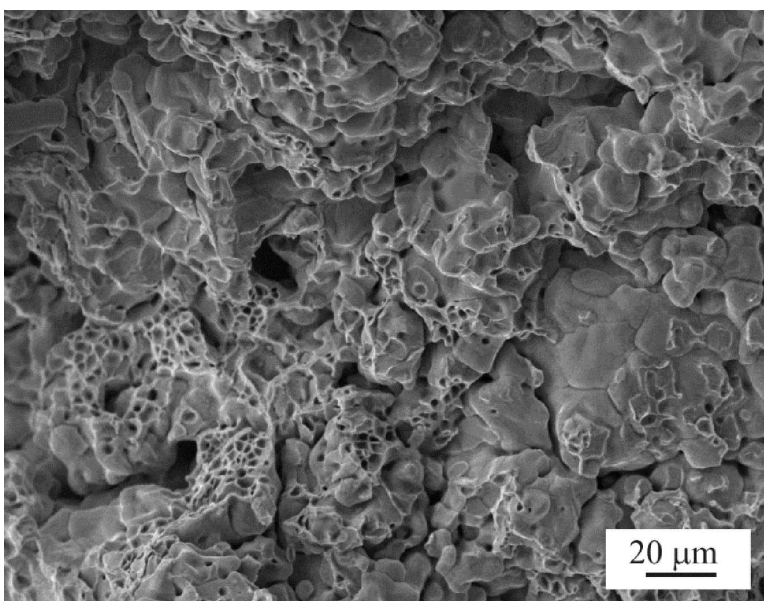

Fig. 3. Microdeformation processes of system FN.

the deformation can distribute into the volume of particles. This is represented by a decrease in the impact energy values and low macrodeformation characteristics. Low values of the TRS underline insufficient development of interparticle bonding during heat treatment, the pores and other internal defects [11-13] developed in the consolidation are detrimental to the mechanical properties. It is well-known that strengthening is attributed to the

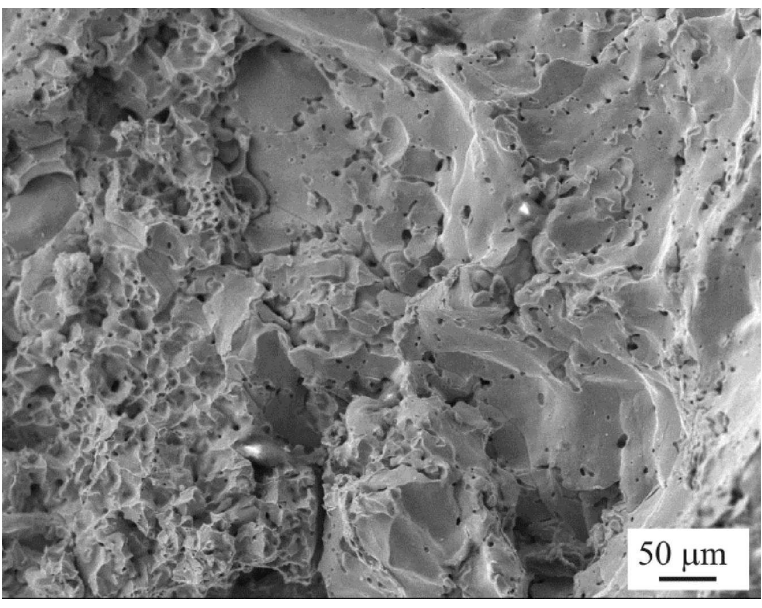

Fig. 4. Microdeformation processes of system I.

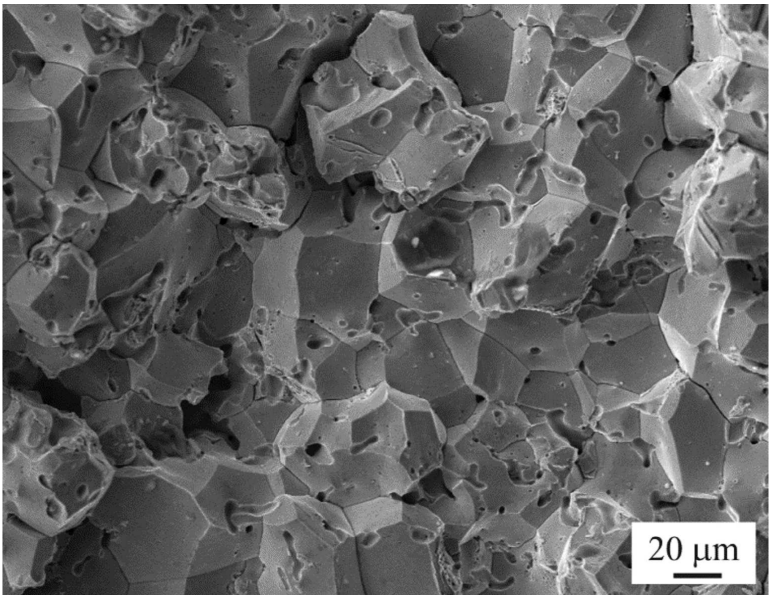

Fig. 5. Microdeformation processes of system P.

pile-up of dislocations at grain boundaries acting as efficient barriers to dislocation motion. Pores and impurities are responsible for the formation of the slip steps by the slip motion of dislocations, preferably on the free surfaces of interparticle bonding. This effect has been termed the negative pile up [5]. Smaller interparticle contacts cannot create a positive "pile up" which initiate the cleavage process and, therefore, they are fractured in a ductile mode, such as is in presented in the material I and FN. This could also be a result of limited strain hardening in the material since strain hardening is important for achieving uniform plastic deformation which is represented by smaller impact energy values (10.5 J for material $\mathrm{FN}$ and $2.5 \mathrm{~J}$ for material I). Forces during sintering cause stronger bond. According to the German [14], these forces are mechanical interlocking, inter-atomic force and electrostatic force across the interface. Inter-atomic force and electrostatic force are stronger with smooth, clean surfaces.

In terms of microdeformation processes, the fractography examination evidences the mix of Type 2 and Type 3. Non-deformational interparticle bonding, developed in locations without metallic connections between 
particles and some local area are consisting of interparticle bonding by plastic deformation of the matrix, correspond to locations with developed metallic connections, and were observed, Figs. 3 and 4 . For material P, location with pronounced plastic deformation, corresponding to microvolumes with well-developed connections, is determined, Fig. 5. As underlined by Dudrova and Kabatova [15], well-developed voluminous necks are mostly represented by ductile dimple facets with localized plastic flow. Therefore, higher mechanical properties are corresponding to the microdeformation processes, because the value of plain porosity and elongation cannot reveal the possibility for understanding higher the value of both mechanical properties, TRS and Rm, $856 \mathrm{MPa}$ and $428 \mathrm{MPa}$, respectively.

\section{Conclusions}

The main interest in the use of PM materials for SMC purposes, if compared to wrought materials, is the general isotropic homogeneity of the components. However, the presence of porosity strongly impact the properties of the material. For this reason, the evaluation of geometry and quality of the interparticle bondings represents an important microstructural characteristic of the porous material. Plain porosity contributes to the recognition of critical microstructural defects and therefore, to enable the evaluation of the relationship between the processing parameters, microstructural constituents, and pores.

As for the fractography evaluation, the evaluation of the interparticle bonding using determination of the elementary types of fracture facets constitutes a key to interpret the mechanical and plastic properties of the investigated materials.

\section{Acknowledgments}

This work was supported by Slovak national agency project code VEGA 1/0732/16.

\section{References}

[1] H. Danninger, G. Jangg, B. Weiss, R. Stickler, Powder Metall. Int. 25, 111 (1993).

[2] M. Dlapka, H. Danninger, Ch. Gierl, B. Lindqvist, Metal Powder Rep. 65, 30 (2010).

[3] M. Slesar, E. Dudrova, E. Rudnayova, Powder Metall. Int. 24, 232 (1992).

[4] E. Dudrova, L. Parilak, K. Pelikan, 251 Sov. Mater. Sci. 28, (1992).

[5] M. Slesar, E. Dudrova, H. Danninger, Kovove Mater. 38, 389 (2000).

[6] J.A. Bas, J.A. Calero, M.J. Dougan, J. Magn. Magn. Mater. 254, 391 (2003).

[7] L.L. Evangelista, D.S. Avila, M.A. Carvalho, H.D. Lopes, P.A.P. Wendhausen, IEEE Trans. Magn. 52, $7378512(2016)$.

[8] H. Shokrollahi, K. Janghorban, J. Mater. Process. Technol. 189, 1 (2007).

[9] A.M. Grande, R. Bidulsky, A. Cavagnino, L. Ferraris, P. Ferraris, IEEE Trans. Ind. Appl. 48, 1335 (2012).

[10] G.F. Vander Voort, Metallography - Principles and Practise, ASM International, 1984.

[11] R. Bidulsky, J. Bidulska, M.A. Grande, L. Ferraris, Acta Metall. Slov. 20, 271 (2014).

[12] R. Kocisko, R. Bidulsky, L. Dragosek, M. Skrobian, Acta Metall. Slov. 20, 302 (2014).

[13] P. Petrousek, T. Kvackaj, R. Kocisko, R. Bidulsky, J. Bidulska, A. Fedorikova, T. Hlava, Acta Metall. Slov. 21, 176 (2015).

[14] R.M. German, Powder Metallurgy Science, 2nd ed., Metal Powder Industries Federation, Princeton 1994.

[15] E. Dudrova, M. Kabatova, Powder Metall. 59, 148 (2016). 